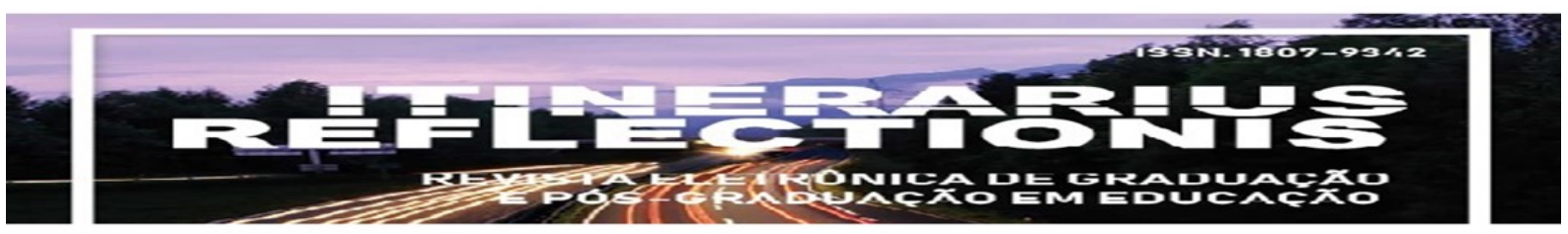

Volume, 15, n,1, ano 2019

\title{
MAPEAMENTO BIBLIOGRÁFICO DA INCLUSÃO DE DEFICIENTES VISUAIS NA APRENDIZAGEM DE MATEMÁTICA
}

\author{
Paulo Sergio de Oliveira Conceição ${ }^{1}$ \\ Carla Lima Santos ${ }^{2}$ \\ Ana Maria Libório ${ }^{3}$ \\ Karla Amâncio Pinto Field's ${ }^{4}$
}

RESUMO: Este artigo tem por objetivo divulgar os resultados parciais sobre a pesquisa do Programa de Iniciação Científica PIBIC/CNPQ que tem como um dos objetivos mapear os artigos publicados sobre educação matemática para deficientes visuais. A metodologia consistiu em analisar as edições das principais revistas de educação matemática, bem como a Revista Benjamim Constant, no período de 2000 a agosto/2018. Foram encontrados e selecionados vinte e oito artigos, entre eles, relatos de

\footnotetext{
${ }^{1}$ Discente de Licenciatura em Matemática, Pesquisador PIBIC/CNPQ. Instituto Federal de Brasília - Campus Estrutural: paulo98mil@gmail.com

${ }^{2}$ Discente de Licenciatura em Matemática, Pesquisadora PIBIC (Voluntária)/CNPQ. Instituto Federal de Brasília - Campus Estrutural: carlasantlim1@gmail.com

${ }^{3}$ Doutoranda em Ciências da Educação, especialidade Educação Matemática na Universidade do Minho em Portugal, Mestra em Estudos Amazônicos pela Universidade Nacional de Colômbia - UNAL/CO (2010), Título revalidado pela Universidade Federal do Amazonas equivalente ao Título de Mestre em Sociedade e Cultura na Amazônia. Especialista em Docência do Ensino Superior - UCAM/RJ (2003) e Graduada em Licenciatura em Ciências e Licenciatura em Matemática pela Universidade de Araxá - MG (1999). Pesquisadora, líder do Núcleo de Estudos e Pesquisas em Educação, Cultura e Sociedade - NEPECS/CNPQ, membro do Grupo de Pesquisa Estudos Geográficos - GPEG/CNPQ, membro do Núcleo de Pesquisa em Matemática, Educação e Sociedade/CNPQ. Professora do Instituto Federal de Educação, Ciência e Tecnologia, atualmente em exercício no IFB - campus Estrutural. Sobretudo, atuando na Formação dos Cursos de Engenharia, Tecnologia e Licenciatura, promovendo as Tendências no Ensino da Matemática em Modelagem, Etnomatemática e Tecnologia, assim como, Matemática Aplicada. analiborio@gmail.com
}

${ }^{4}$ Professora do Instituto Federal de Goiás-Campus Itumbiara em Exercício Provisório no IFB Campus Estrutural. Doutora em Química pela Universidade Federal de Goiás, Mestre em Química pela Universidade Federal de Uberlândia (2001). Licenciada em Química pela Universidade Federal de Uberlândia (2002). Pesquisadora do Núcleo de Pesquisa e Extensão em Processos Educacionais (NuPEPE) do Instituto Federal de Educação, Ciência e Tecnologia de Goiás, Câmpus Itumbiara. Pesquisadora do Núcleo de Pesquisa Matemática, Educação e Sociedade, do IFB Campus Estrutural. Colaboradora do Laboratório de Pesquisas em Educação Química e Inclusão (LPEQI) da Universidade Federal de Goiás (UFG). Experiência em formação de professores de Química e elaboração de sequência didática.karla.fields@ifb.edu.br 


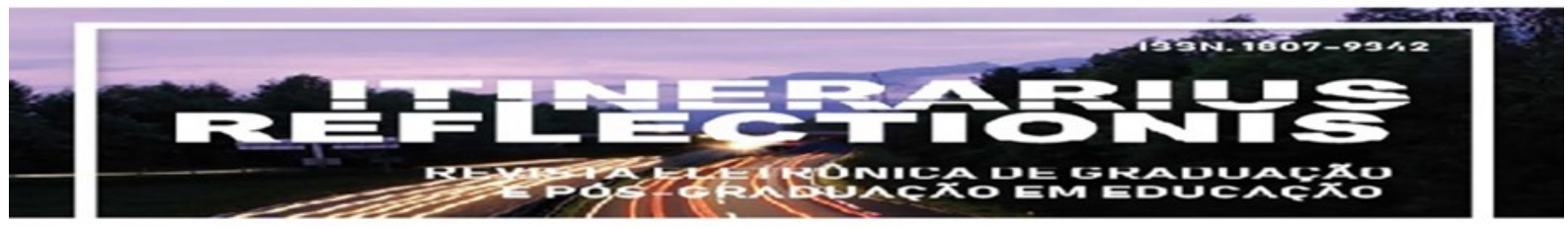

\title{
Volume 15, número 1, ano,2019
}

experiência, entrevistas e resumo de dissertação. Os resultados apontam que o maior número de publicação é da Revista Benjamim Constant, revista dedicada à publicação de artigos relacionados à temática da deficiência visual em seus diversos desdobramentos. Nas outras revistas a quantidade de artigos publicados é bem restrito, o que evidencia que o tema é pouco explorado, sendo necessário intensificar as pesquisas nessa linha. Uma proposta para se reverter esse quadro é incluir projetos de pesquisa na área de inclusão nos cursos de licenciatura, pois é necessário que futuros professores tenham condições de planejar aulas relativas às especificidades desse público.

Palavras-Chave: Educação matemática. Deficientes visuais. Mapeamento bibliográfico.

\section{BIBLIOGRAPHICAL PLOTTING OF THE INCLUSION OF VISUAL DEFICIENT IN THE MATHEMATICS LEARNING}

\begin{abstract}
This paper aims to disseminate the partial results on the research of the Program of Scientific Initiation PIBIC / CNPQ that has as one of the objectives to map the published articles on mathematical education for the visually impaired. The methodology consisted in analyze the main magazines editions of mathematical education, as well as the Magazine Benjamin Constant, in the period from 2000 to agosto/2018. They were found and selected twenty-eight goods, among them, experience reports, dissertation interviews and summary. The results point that the biggest number of publication belongs to the Magazine Benjamin Constant, magazine dedicated to the goods publication related to thematic of the visual deficiency in their several unfoldings. In the other magazines the quantity of published goods is very restricted, what evidences that the theme is little explored, being necessary to intensify the researches in this line. A proposal to if revert that picture is to include research projects in the inclusion area in graduation courses, because it is necessary how future teachers have terms of planing relative classes to the specificities of this public.
\end{abstract}

Keywords: Mathematical education. Visual deficient. Bibliographical plotting. 

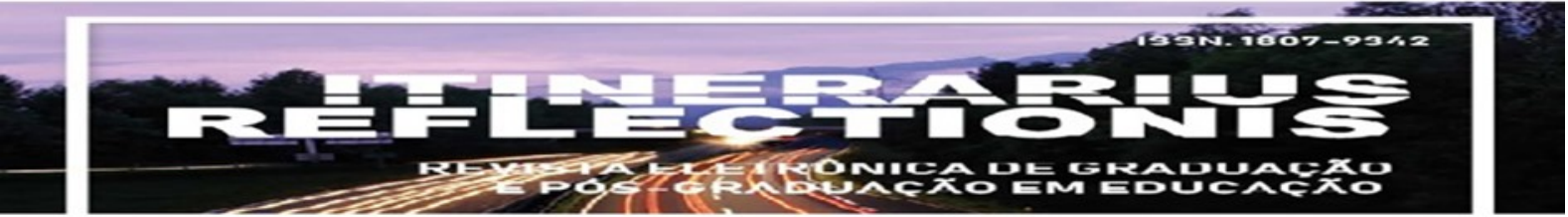

\section{Volume 15, número 1, ano,2019}

\section{INTRODUÇÃO}

Em 1996 foi constituída a Lei $n^{\circ}$ 9.394/96 da Lei e Diretrizes de Base da Educação (LDB), em seu capítulo III, art. $4^{\circ}$, inciso $4^{\circ}$, foi decretado que o estado tem por dever assegurar o atendimento especializado gratuito aos educandos com necessidades especiais, preferivelmente na rede regular de ensino. $\mathrm{O}$ artigo $58 \S 1^{\circ}$ institui que, quando necessário, haverá serviço de apoio especializado para atender as necessidades específicas de cada aluno portador de necessidades especiais (BRASIL, 1996).

Porém, para que tais ações possam ser efetivas é primordial que haja uma preparação especializada para o professor que trabalhará com tais alunos com necessidades educacionais especiais (NEEs). A esse respeito, no art. 59, inciso III, está declarado que os sistemas de ensino devem assegurar que professores, com especialização adequada em nível médio ou superior, realizem o atendimento especializado aos educandos, assim como professores do ensino regular capacitados para a integração desses alunos em classes comuns (BRASIL, 1996).

Todavia, faz-se necessário que a escola e os professores sejam capazes de incluílos efetivamente na rotina de ensino e aprendizagem na sala de aula para além da integração. Para Sanches e Teodoro (2006), dar-se as seguintes diferenças entre uma educação inclusiva e uma educação integrada:

I) A integração diz respeito às necessidades educativas especiais, às medidas complementares necessárias para responder aos alunos especiais. Em linhas gerais, trata-se de um sistema educativo que não é alterado, sua perspectiva é centrada na criança.

II) A inclusão visa a educação necessária para todos, suas medidas complementares procuram suprir as necessidades educativas de todos os alunos, sua metodologia e organização sofre mudanças conforme as necessidades de aprendizagem, sua perspectiva é centrada no currículo.

Tratando-se de inclusão é perceptível que os desafios são diários, e esses desafios talvez sejam ainda maiores quando se trata de uma educação inclusiva para alunos com 

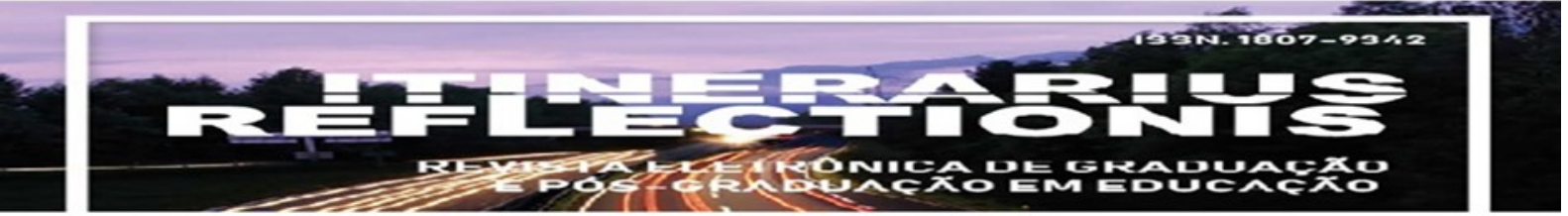

\section{Volume 15, número 1, ano,2019}

deficiência visual (DV). Considerando esse aspecto, decidiu-se realizar uma pesquisa científica para identificar o que tem sido realizado para garantir a inclusão dos alunos com DV no processo de ensino e aprendizagem de matemática. Essa escolha justifica-se, de forma particular, pelo fato de a pesquisa estar sendo realizada no Instituto Federal de Brasília (IFB), Campus Estrutural, no qual é ofertada a Licenciatura em Matemática.

Para que se possa discutir a respeito do que pode ser feito para assegurar a inclusão de alunos DV, primeiramente faz-se necessária a realização do levantamento da literatura existente sobre o tema. Tendo esse aspecto em consideração, o presente artigo tem por objetivo mapear as publicações sobre a educação matemática para DV.

\section{METODOLOGIA}

Esta é uma investigação de cunho qualitativo que tem por objetivo identificar artigos publicados na área de educação matemática voltadas ao ensino de DV. Foi realizada uma pesquisa bibliográfica em periódicos voltados para educação matemática e em um periódico específico de deficiência visual.

A investigação foi realizada no período 2000 a 2018, nas seguintes revistas: Matemática Universitária; International Journal For Research In Mathematics Education; Educação Matemática em Revista; Bolema (Boletim de Educação Matemática); Revista Benjamin Constant. Optou por fazer um levantamento bibliográfico de dezoito anos para identificar o que já foi pesquisado nessa linha.

Em cada uma das revistas citadas reuniu-se as edições publicadas entre $2000 \mathrm{e}$ 2018, e em cada edição selecionou-se as publicações cujo resumo/título entrava na temática de educação matemática para cegos ou DV.

\section{RESULTADOS E DISCUSSÃO}




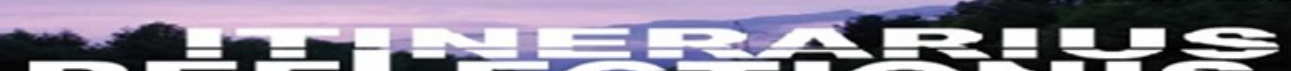 (1) स्य,}

\section{Volume 15, número 1, ano,2019}

Foram selecionados vinte e oito artigos publicados de janeiro/2000 a agosto/2018 nos cinco periódicos citados anteriormente, que abordam a temática de educação matemática para DV, seja ela uma discussão do método de ensino, do material para ensino ou discussões sobre o ensino de matemática para educandos deficientes visuais. O Quadro 1 apresenta os artigos publicados selecionados.

Quadro 1: Artigos selecionados.

\begin{tabular}{|c|c|c|c|c|}
\hline & Título do Artigo & Autor(es) & Revista & Ano \\
\hline 01 & $\begin{array}{l}\text { Tecnologias Concretas e Digitais } \\
\text { Aplicadas ao Processo de Ensino- } \\
\text { Aprendizagem de Matemática } \\
\text { Inclusiva. }\end{array}$ & $\begin{array}{l}\text { FIGUEROA, T. P.; } \\
\text { et al. }\end{array}$ & $\begin{array}{l}\text { Educação Matemática } \\
\text { em Revista }\end{array}$ & 2011 \\
\hline $\mathbf{0 2}$ & $\begin{array}{l}\text { Inclusão no Ensino Médio: Geometria } \\
\text { para Deficiente Visual. }\end{array}$ & $\begin{array}{l}\text { SILVA, D. C.; } \\
\text { LEIVAS, J. C. S. }\end{array}$ & $\begin{array}{l}\text { Educação Matemática } \\
\text { em Revista }\end{array}$ & 2013 \\
\hline 03 & $\begin{array}{l}\text { Adaptações no Software GeoGebra } \\
\text { para Alunos com Baixa Visão. }\end{array}$ & $\begin{array}{l}\text { PAPACOSTA, A. } \\
\text { R.; } \\
\text { CIVARDI, J. A.; } \\
\text { DIAS, M. E. S. }\end{array}$ & $\begin{array}{l}\text { Educação Matemática } \\
\text { em Revista }\end{array}$ & 2015 \\
\hline 04 & $\begin{array}{l}\text { Representações Sociais } \\
\text { de Estudante Cego } \\
\text { Aprender Matemática por } \\
\text { Professores de } \\
\text { Matemática. }\end{array}$ & $\begin{array}{l}\text { LANDIM E.; } \\
\text { MAIA L. S. L.; } \\
\text { SOUSA, W. P. A. }\end{array}$ & $\begin{array}{l}\text { Educação Matemática } \\
\text { em Revista }\end{array}$ & 2017 \\
\hline 05 & $\begin{array}{c}\text { Educação matemática em uma } \\
\text { perspectiva inclusiva: percepções de } \\
\text { professores e alunos deficientes } \\
\text { visuais. }\end{array}$ & $\begin{array}{l}\text { RODRIGUES, J. } \\
\text { M.; } \\
\text { SALES, E. R. }\end{array}$ & $\begin{array}{l}\text { Educação Matemática } \\
\text { em Revista }\end{array}$ & 2018 \\
\hline 06 & O estudo da Geometria. & BARBOSA, P. M. & $\begin{array}{l}\text { Revista Benjamin } \\
\text { Constant }\end{array}$ & 2003 \\
\hline
\end{tabular}




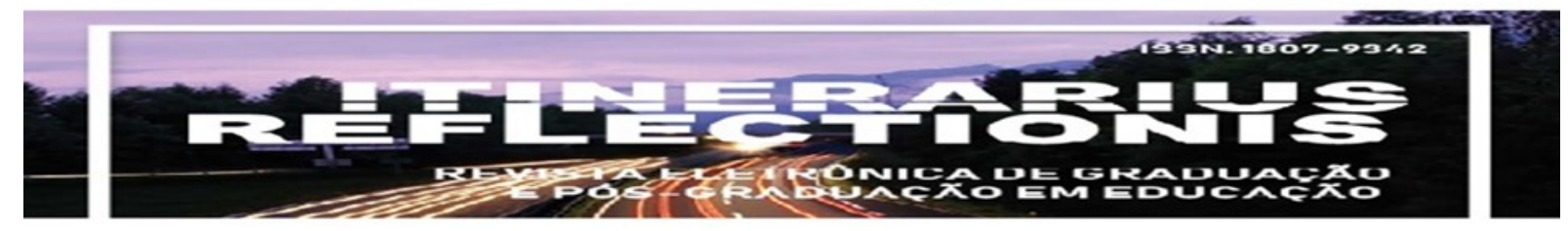

\section{Volume 15, número 1, ano,2019}

\begin{tabular}{|c|c|c|c|c|}
\hline 07 & $\begin{array}{l}\text { Uma Perspectiva Walloniana no } \\
\text { Ensino de Matemática para Deficiente } \\
\text { Visual Através dos Sons e Ritmos. }\end{array}$ & MOTTA, C. E. M. & $\begin{array}{l}\text { Revista Benjamin } \\
\text { Constant }\end{array}$ & 2004 \\
\hline 08 & Geumetria $=\mathrm{Eu}+$ Geometria. & BRANDÃO, J. C. & $\begin{array}{l}\text { Revista Benjamin } \\
\text { Constant }\end{array}$ & 2004 \\
\hline 09 & $\begin{array}{c}\text { De Lá Pra Cá... Daqui Pra Lá... Tanto } \\
\text { Faz... - As Operações Matemáticas nas } \\
\text { Velhas Tábuas de Contar. }\end{array}$ & $\begin{array}{l}\text { FERNANDES, C. } \\
\text { T. }\end{array}$ & $\begin{array}{l}\text { Revista Benjamin } \\
\text { Constant }\end{array}$ & 2006 \\
\hline 10 & $\begin{array}{c}\text { Desenho Geométrico e Deficiência } \\
\text { Visual. }\end{array}$ & BRANDÃO, J. C. & $\begin{array}{l}\text { Revista Benjamin } \\
\text { Constant }\end{array}$ & 2008 \\
\hline 11 & $\begin{array}{c}\text { A matemática por trás da orientação e } \\
\text { mobilidade. }\end{array}$ & BRANDÃO, J. & $\begin{array}{l}\text { Revista Benjamin } \\
\text { Constant }\end{array}$ & 2009 \\
\hline 12 & $\begin{array}{l}\text { Buscando a Educação Inclusiva em } \\
\text { Geometria. }\end{array}$ & $\begin{array}{l}\text { KALEFF, A. M.; } \\
\text { ROSA, F. M. }\end{array}$ & $\begin{array}{l}\text { Revista Benjamin } \\
\text { Constant }\end{array}$ & 2012 \\
\hline 13 & $\begin{array}{c}\text { Atividades Desenvolvidas com o } \\
\text { Material Dourado. }\end{array}$ & $\begin{array}{l}\text { TURELLA, C. F.; } \\
\text { CONTI, K. C. }\end{array}$ & $\begin{array}{l}\text { Revista Benjamin } \\
\text { Constant }\end{array}$ & 2012 \\
\hline 14 & $\begin{array}{l}\text { O ensino de matemática para pessoas } \\
\text { com deficiência visual no Brasil: um } \\
\text { estudo bibliográfico. }\end{array}$ & $\begin{array}{l}\text { COSTA, A. B.; } \\
\text { COZENDEY, S. G. }\end{array}$ & $\begin{array}{l}\text { Revista Benjamin } \\
\text { Constant }\end{array}$ & 2014 \\
\hline 15 & $\begin{array}{l}\text { Proposta para o ensino de conteúdos de } \\
\text { matemática a estudantes cegos. }\end{array}$ & $\begin{array}{l}\text { MOLLOSSI, L. F. } \\
\text { S. B.; } \\
\text { MENESTRINA, T. } \\
\text { C.; MANDLER, M. } \\
\text { L }\end{array}$ & $\begin{array}{l}\text { Revista Benjamin } \\
\text { Constant }\end{array}$ & 2014 \\
\hline 16 & $\begin{array}{l}\text { Matemática inclusiva em ação: um } \\
\text { estudo de caso de deficiência visual na } \\
\text { Educação Básica. }\end{array}$ & $\begin{array}{l}\text { CONCEIÇÃO, } \\
\text { G.L.; } \\
\text { RODRIGUES, C. } \\
\text { K. }\end{array}$ & $\begin{array}{l}\text { Revista Benjamin } \\
\text { Constant }\end{array}$ & 2014 \\
\hline 17 & $\begin{array}{l}\text { Uma perspectiva sobre a inclusão de } \\
\text { cegos: considerações de uma } \\
\text { professora de matemática. }\end{array}$ & $\begin{array}{l}\text { MOLLOSSI, L. F. } \\
\text { S. B.; } \\
\text { MENESTRINA, T. } \\
\text { C.; MANDLER, M. } \\
\text { L.; MENESTRINA, } \\
\text { L. C. }\end{array}$ & $\begin{array}{l}\text { Revista Benjamin } \\
\text { Constant }\end{array}$ & 2015 \\
\hline 18 & Argumentação e prova em matemática: & CARVALHO, M. & Revista Benjamin & 2016 \\
\hline
\end{tabular}




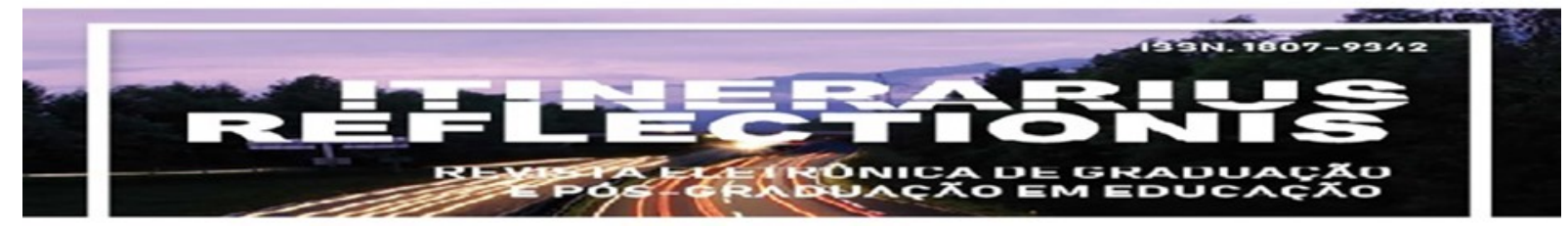

\section{Volume 15, número 1, ano,2019}

\begin{tabular}{|c|c|c|c|c|}
\hline & $\begin{array}{l}\text { análise de um estudo realizado com } \\
\text { alunos cegos. }\end{array}$ & $\begin{array}{c}\text { A. A.; } \\
\text { VIANNA, C. C. S }\end{array}$ & Constant & \\
\hline 19 & $\begin{array}{l}\text { Horizontes da Educação Matemática } \\
\text { Inclusiva envolvendo cegos: mapeando } \\
\text { teses e dissertações. }\end{array}$ & $\begin{array}{l}\text { MOLLOSSI, L. F. } \\
\text { S. B.; AGUIAR, R.; } \\
\text { MORETTI, M. T. }\end{array}$ & $\begin{array}{l}\text { Revista Benjamin } \\
\text { Constant }\end{array}$ & 2016 \\
\hline 20 & $\begin{array}{l}\text { Observação da revisão de gráficos e } \\
\text { tabelas de Estatística adaptados em } \\
\text { livros didáticos de Matemática em } \\
\text { Braille produzidos pelo Instituto } \\
\text { Benjamin Constant. }\end{array}$ & $\begin{array}{l}\text { SANTOS, R. C.; } \\
\text { VIANNA, C. C. S. }\end{array}$ & $\begin{array}{l}\text { Revista Benjamin } \\
\text { Constant }\end{array}$ & 2017 \\
\hline 21 & $\begin{array}{l}\text { Teaching mathematics for blind } \\
\text { students: a challenge at the university. }\end{array}$ & $\begin{array}{l}\text { MARCONE, R.; } \\
\text { PENTEADO, M. } \\
\text { G. }\end{array}$ & $\begin{array}{l}\text { International Journal For } \\
\text { Research In } \\
\text { Mathematics Education }\end{array}$ & 2013 \\
\hline 22 & $\begin{array}{l}\text { Multimodality and mathematical } \\
\text { meaning-making: Blind students' } \\
\text { interactions with Symmetry. }\end{array}$ & $\begin{array}{l}\text { FERNANDES, S. } \\
\text { H. A. A.; HEALY, } \\
\text { L. }\end{array}$ & $\begin{array}{l}\text { International Journal For } \\
\text { Research In } \\
\text { Mathematics Education }\end{array}$ & 2013 \\
\hline 23 & $\begin{array}{c}\text { A tecnologia informática como auxílio } \\
\text { no ensino de geometria para } \\
\text { deficientes visuais. }\end{array}$ & LIRIO, S. B. & BOLEMA & 2006 \\
\hline 24 & $\begin{array}{l}\text { As "Ticas" de "Matema" de Cegos Sob } \\
\text { o Viés Institucional: da Integração à } \\
\text { Inclusão. }\end{array}$ & CALORE, A. C. O. & BOLEMA & 2009 \\
\hline 25 & $\begin{array}{l}\text { A Inclusão de Alunos Cegos nas Aulas } \\
\text { de Matemática: explorando Área, } \\
\text { Perímetro e Volume através do Tato. }\end{array}$ & $\begin{array}{l}\text { FERNANDES, S. } \\
\text { H. A. A.: } \\
\text { HEALY, L. }\end{array}$ & BOLEMA & 2010 \\
\hline 26 & $\begin{array}{c}\text { Inclusão de Estudantes Cegos nas } \\
\text { Aulas de Matemática: a construção de } \\
\text { um kit pedagógico. }\end{array}$ & ULIANA, M. R. & BOLEMA & 2013 \\
\hline 27 & $\begin{array}{l}\text { A Negociação de Sinais em Libras } \\
\text { como Possibilidade de Ensino e de } \\
\text { Aprendizagem de Geometria. }\end{array}$ & $\begin{array}{l}\text { SALES, E. R. S.; } \\
\text { et al. }\end{array}$ & BOLEMA & 2015 \\
\hline 28 & $\begin{array}{l}\text { O uso de narrativas (auto)biográficas } \\
\text { como uma possibilidade de pesquisa da } \\
\text { prática de professores acerca da } \\
\text { Educação (Matemática) Inclusiva. }\end{array}$ & $\begin{array}{l}\text { ROSA, F. M. C.; } \\
\quad \text { et al. }\end{array}$ & BOLEMA & 2015 \\
\hline
\end{tabular}




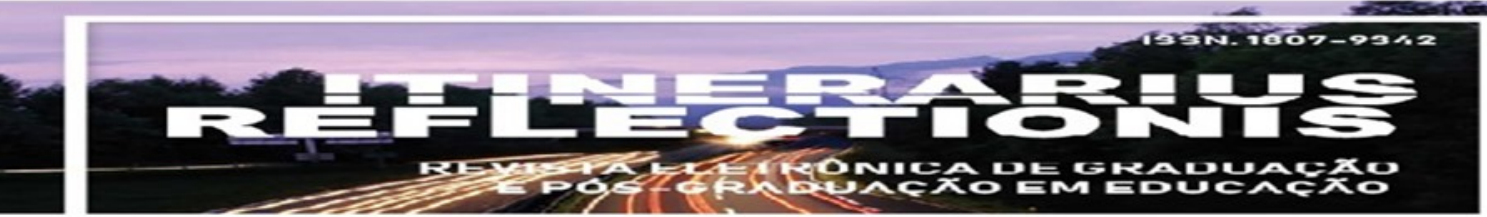

Volume 15, número 1, ano,2019

Fonte: Elaborado pelo autor

É evidente que o maior número de publicações no intervalo de 18 anos veio por parte da Revista Benjamin Constant (RBC). Para melhor visualização do número publicações por revista, tem-se, no Gráfico 1, o número de artigos enquadrados na temática publicados em cada revista.

Gráfico 1: Publicações por revista

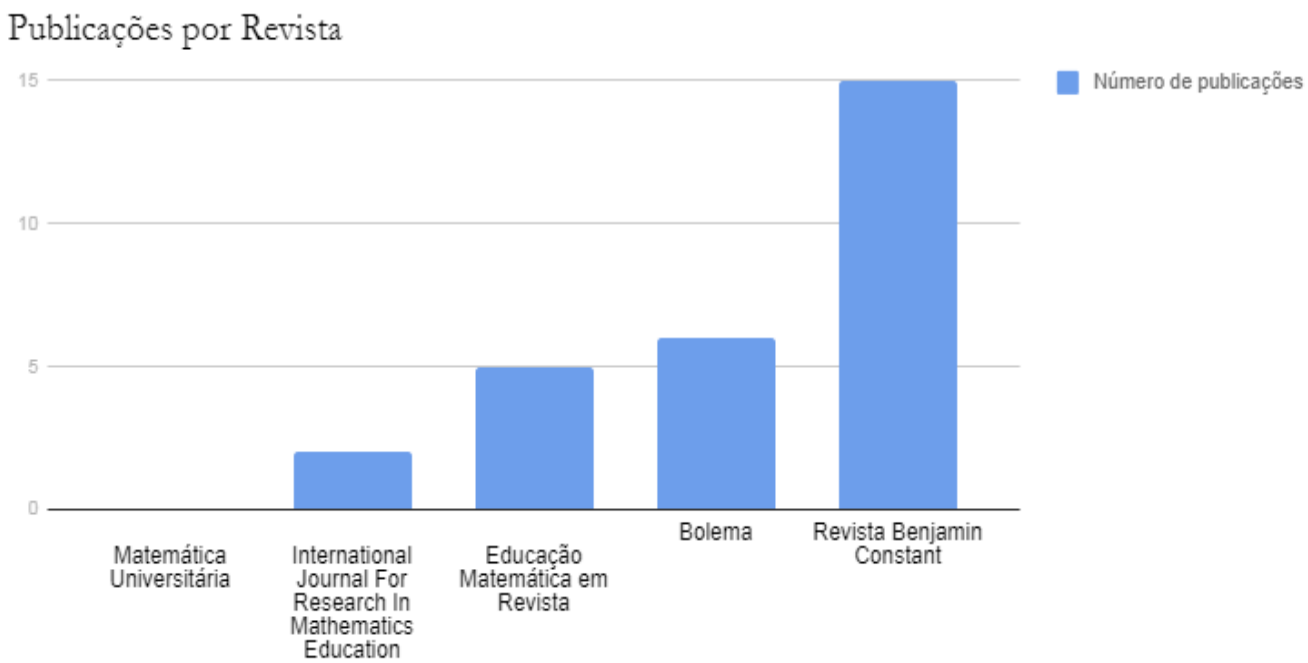

Fonte: Elaborado pelo autor.

O gráfico 1 evidencia que a RBC é responsável por mais da metade das publicações enquadradas na temática proposta. Essa revista é publicada semestralmente pelo Instituto Benjamim Constant e tem como objetivo publicar trabalhos originais e inéditos que contribuam para o conhecimento e desenvolvimento da pesquisa na área da deficiência visual. A temática da RBC é deficiência visual e as modalidades dos trabalhos publicados nessa revista podem ser artigos científicos, relatos de experiência, revisão da literatura e resenha crítica. Por ser uma revista específica da área de deficiência visual e por ser publicada pelo Instituto Benjamim Constant é com certeza uma referência na área. O Instituto Benjamim 


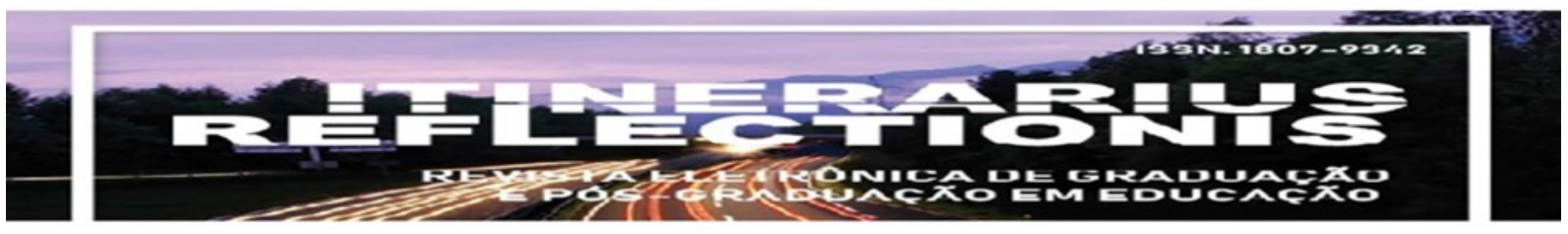

\section{Volume 15, número 1, ano,2019}

Constant, localizado na cidade do Rio de Janeiro é mais do que uma escola que atende crianças e adolescentes com deficiência visual é:

Também um centro de referência, a nível nacional, para questões da deficiência visual, capacitando profissionais e assessorando instituições públicas e privadas nessa área, além de reabilitar pessoas que perderam ou estão em processo de perda da visão. Ao longo dos anos, o IBC tornou-se também um centro de pesquisas médicas no campo da Oftalmologia, possuindo um dos programas de residência médica mais respeitados do País. Através desse programa, presta serviços de atendimento médico à população, realizando consultas, exames e cirurgias oftalmológicas. O Instituto é comprometido também com a produção e difusão da pesquisa acadêmica no campo da Educação Especial. Através da Imprensa Braille, edita e imprime livros e revistas em Braille, além de contar com um farto acervo eletrônico de publicações científicas. (http://www.ibc.gov.br/o-ibc)

No Gráfico 2, tem-se o número de publicações em cada ano por revista e o total de publicações no ano.

\section{Gráfico 2: Publicações por ano}

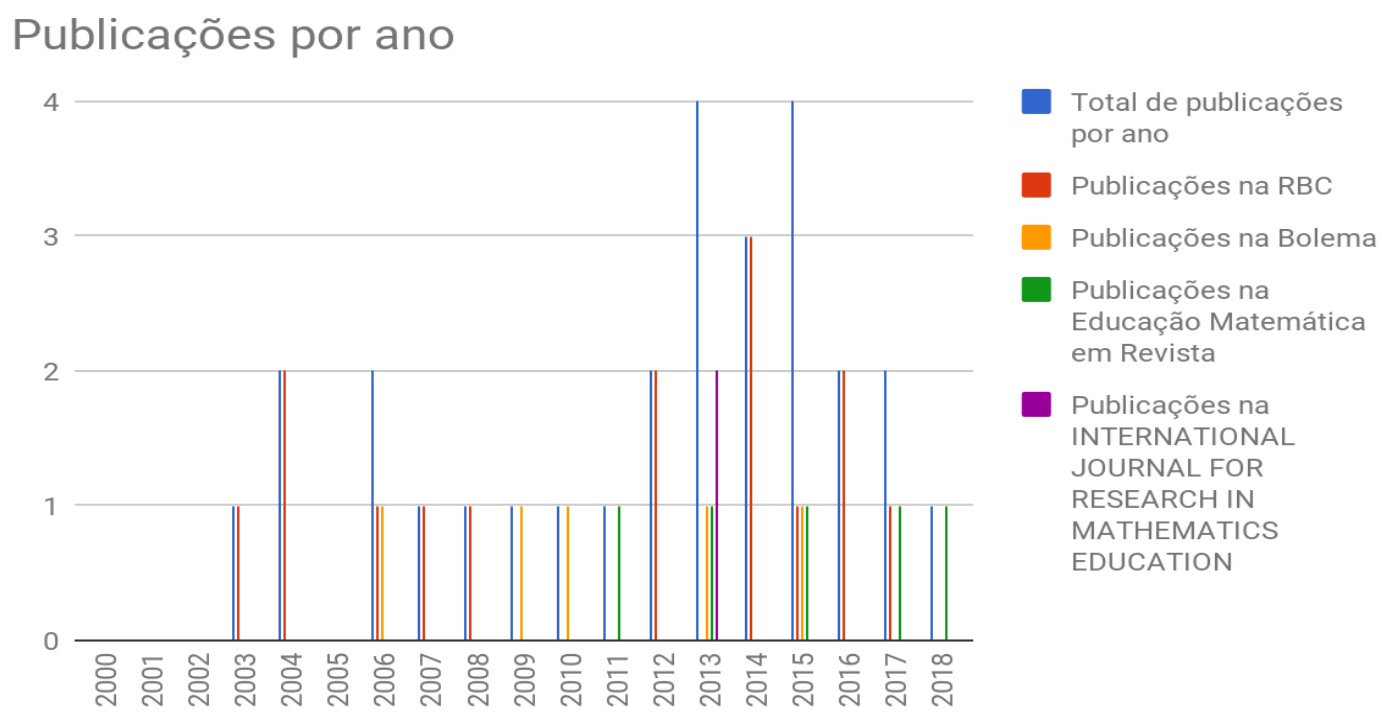

Fonte: Elaborado pelo autor.

Vê-se no gráfico acima que, de 2000 a 2010, foram publicados apenas dez artigos voltados para o ensino de matemática para alunos deficientes visuais, sendo cinco destas 

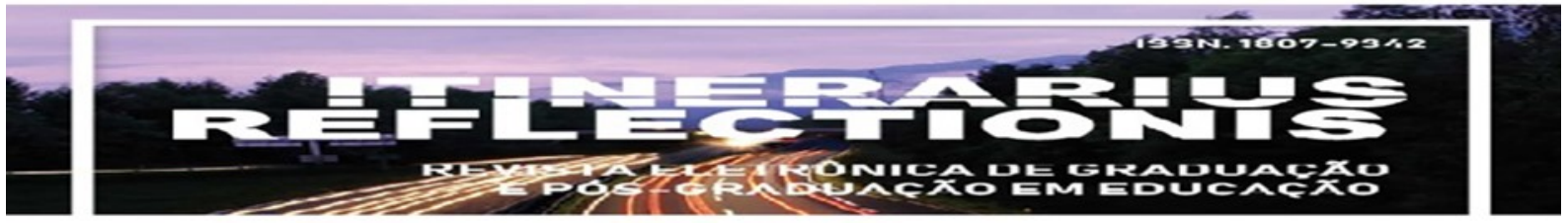

\section{Volume 15, número 1, ano,2019}

publicações na RBC, revista voltada para a temática deficiência visual. De 2011 até o agosto de 2018, foram publicados dezenove artigos, o que demonstra um crescimento significativo de $90 \%$, em oito anos. Entretanto, considerando-se os números encontrados, ainda é uma quantidade pouca de artigos referentes a essa temática, e, novamente, notamos que neste período o maior número de artigos veio por parte da RBC.

Segundo Leitão e Fernandes (2011, p. 11), “existe uma ausência de estudos empíricos que discutam metodologias de ensino e analisem a capacidade cognitiva de alunos DV, e essa ausência é um ponto importante a ser considerado e uma lacuna a ser preenchida."

\section{CONSIDERAÇÕES FINAIS}

Nesse artigo, foi realizado um mapeamento dos artigos publicados em quatro revistas de educação matemática e uma revista voltada para a temática de DV. Foram selecionados os artigos que abordaram o tema educação matemática para deficientes visuais, no período de 2000 a 2018. Por meio desses dados, observou-se que o número de artigos publicados é bem restrito, o que evidencia que o tema é pouco explorado.

$\mathrm{O}$ maior número de publicações ainda vem pela $\mathrm{RBC}$, revista especificamente voltada para a área de deficiência visual. Considerando-se esses dados, cabe investigar o motivo da falta de pesquisas nessa área por parte dos educandos de matemática, pois o número de alunos com DV na rede regular de ensino tem aumentado significativamente nos últimos anos. No início do ano de 2018, em conversa informal com uma professora cega que lecionava a matéria de atividades em uma escola para atendimento especializado de deficientes visuais em Brasília, ela ressaltou a falta de profissionais preparados para lidar com o ensino de alunos DV. Relatou ainda que muitos alunos vão procurar atendimento naquela escola para que possam adquirir os conhecimentos necessários para conseguir se incluir na rede regular de ensino.

O relato da professora ressalta a ausência de profissionais devidamente formados para atender a essa demanda, o que termina por levar os alunos com deficiência visual a 

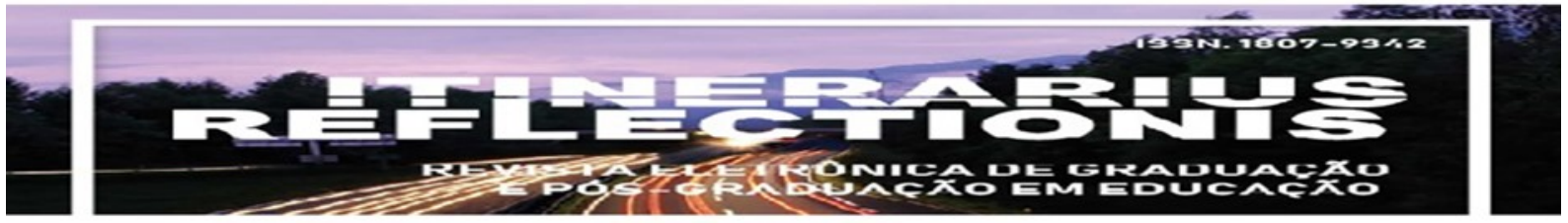

\section{Volume 15, número 1, ano,2019}

procurar, por eles mesmo, meios de serem incluídos no meio escolar, a fim de serem prejudicados. É preciso intensificar as pesquisas nessa área, que por sinal é vasta. Uma proposta para se reverter esse quadro é incluir projetos de pesquisa na área de inclusão nos cursos de licenciatura, pois é necessário que alunos DV sejam adequadamente incluídos na rede regular de ensino e que tenham uma educação de qualidade, uma vez que é de direito tais condições.

Identifica-se que já há um crescimento nas pesquisas e artigos publicados. Logo, pode-se supor que as concepções acerca de ensino de matemática para alunos deficientes visuais tenham evoluído. No entanto, para se comprovar esse crescimento, faz-se necessária a realização de novas pesquisas, o que pode ser efetivado por meio da Iniciação Científica.

\section{REFERÊNCIAS}

BARBOSA, P. M. O estudo da Geometria. Revista Benjamin Constant, Edição 25, agosto, não paginado, 2003.

BRANDÃO, J. A matemática por trás da orientação e mobilidade. Revista Benjamin Constant, n. 41, p. 20-27, 2009.

BRANDÃO, J. C. Desenho Geométrico e Deficiência Visual. Revista Benjamin Constant, Edição 39, abril, não paginado, 2008.

BRANDÃO, J. C. Geumetria= Eu+ Geometria. Revista Benjamin Constant, n. 28, p. 16-21, 2004.

BRASIL. Lei no 9.394. Estabelece as Diretrizes e Bases da Educação Nacional, de 20 de dezembro de 1996. Presidência da República. Brasília, DF.

CALORE, A. C. O. As "Ticas" de "Matema" de Cegos Sob o Viés Institucional: da Integração à Inclusão. BOLEMA (Boletim de Educação Matemática). v. 22, n. 32, 2009. 

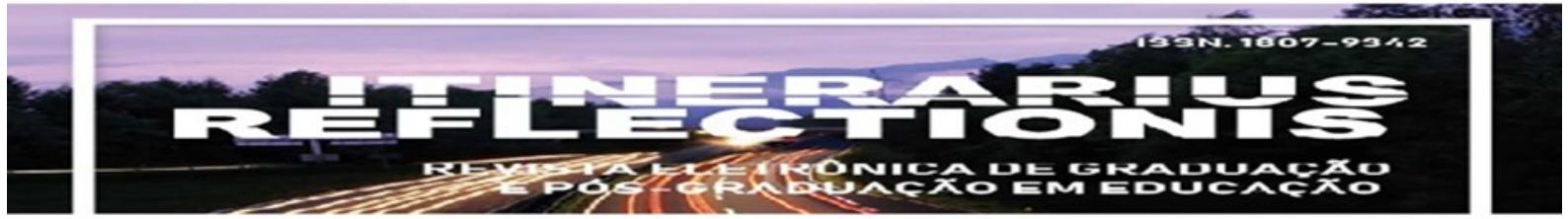

Volume 15, número 1, ano,2019

CARVALHO, M. A. A.; VIANNA, C. C. S. Argumentação e prova em matemática: análise de um estudo realizado com alunos cegos. Revista Benjamin Constant. Edição 59 - v.1, p. 59-79, 2016.

CONCEIÇÃO, G. L.; RODRIGUES, C. K. Matemática inclusiva em ação: um estudo de caso de deficiência visual na Educação Básica. Revista Benjamin Constant. Edição 57 - v. 2, não paginado, 2014.

COSTA, A. B.; COZENDEY, S. G. O ensino de matemática para pessoas com deficiência visual no Brasil: um estudo bibliográfico. Revista Benjamin Constant. Edição 57 - v.1, não paginado,2014.

FERNANDES, C. T. De Lá Pra Cá... Daqui Pra Lá... Tanto Faz... - As Operações Matemáticas nas Velhas Tábuas de Contar. Revista Benjamin Constant, Edição 35, não paginado, 2006.

FERNANDES, S. H. A. A.; HEALY, L. A Inclusão de Alunos Cegos nas Aulas de Matemática: explorando Área, Perímetro e Volume através do Tato. BOLEMA (Boletim de Educação Matemática). V.23, n. 37, 2010.

FERNANDES, S. H. A. A.; HEALY, L. Multimodality and mathematical meaning-making: Blind students' interactions with Symmetry. International Journal for Research in Mathematics Education. v.3, N. 1, 2013.

FIGUEROA, T. P.; FÁVERO, M. B. F.; ALMEIDA, B. L. C.; SANTOS, J. R. Tecnologias Concretas e Digitais Aplicadas ao Processo de Ensino-Aprendizagem de Matemática Inclusiva. Educação Matemática em Revista. Ano 19, n. 32, p. 52-60, 2011.

KALEFF, A. M.; ROSA, F. M. Buscando a Educação Inclusiva em Geometria. Revista Benjamin Constant, Edição 51, abril, não paginado, 2012.

LANDIM E.; MAIA L. S. L.; SOUSA, W. P. A. Representações Sociais de Estudante Cego Aprender Matemática por Professores de Matemática. Educação Matemática em Revista, Brasília, v. 22, n. 54, p. 67-80, abr.jun. 2017.

LEITÃO, J. C.; FERNANDES, C. T. Inclusão escolar de sujeitos com deficiência visual na rede regular de ensino brasileira: revisão sistemática. Revista Linhas Críticas, Brasília, DF, v. 17, n. 33, p. 273-289, maio/ago. 2011. 

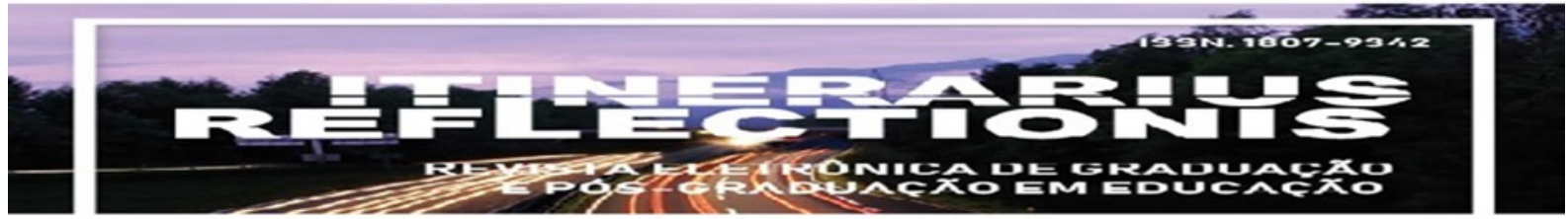

Volume 15, número 1, ano,2019

LIRIO, S. B. A tecnologia informática como auxílio no ensino de geometria para deficientes visuais. BOLEMA (Boletim de Educação Matemática). Volume 19, n. 26, p.171-172, 2006.

MARCONE, R.; PENTEADO, M. G. Teaching mathematics for blind students: a challenge at the university. International Journal for Research in Mathematics Education. Volume 3, N. 1, 2013.

MOLLOSSI, L. F. S. B.; AGUIAR, R.; MORETTI, M. T. Horizontes da Educação Matemática Inclusiva envolvendo cegos: mapeando teses e dissertações. Revista Benjamin Constant. Edição 59 - V.2, p.110-135. 2016.

MOLLOSSI, L. F. S. B.; MENESTRINA, T. C.; MANDLER, M. L. Proposta para o ensino de conteúdos de matemática a estudantes cegos. Revista Benjamin Constant. Edição 57 - v. 1, não paginado, 2014.

MOLLOSSI, L. F. S. B.; MENESTRINA, T. C.; MANDLER, M. L.; MENESTRINA, L. C. Uma perspectiva sobre a inclusão de cegos: considerações de uma professora de matemática. Revista Benjamin Constant. Edição 58 - v.1, não paginado. 2015.

MOTTA, C. E. M. Projeto DRUMATH: Uma Perspectiva Walloniana no Ensino de Matemática para Deficiente Visual Através dos Sons e Ritmos. Revista Benjamin Constant, p. 11-19, 2004.

PAPACOSTA, A. R.; CIVARDI, J. A.; DIAS, M. E. S. Adaptações no Software GeoGebra para Alunos com Baixa Visão. Educação Matemática em Revista, p. 21-28, 2015.

RODRIGUES, J. M.; SALES, E. R. Educação matemática em uma perspectiva inclusiva: percepções de professores e alunos deficientes visuais. Educação Matemática em Revista, p. 23-33, 2018.

ROSA, F. M. C.; BARALDI, I. M. O uso de narrativas (auto)biográficas como uma possibilidade de pesquisa da prática de professores acerca da Educação (Matemática) Inclusiva. BOLEMA (Boletim de Educação Matemática).v. 29, n. 53, 2015. 


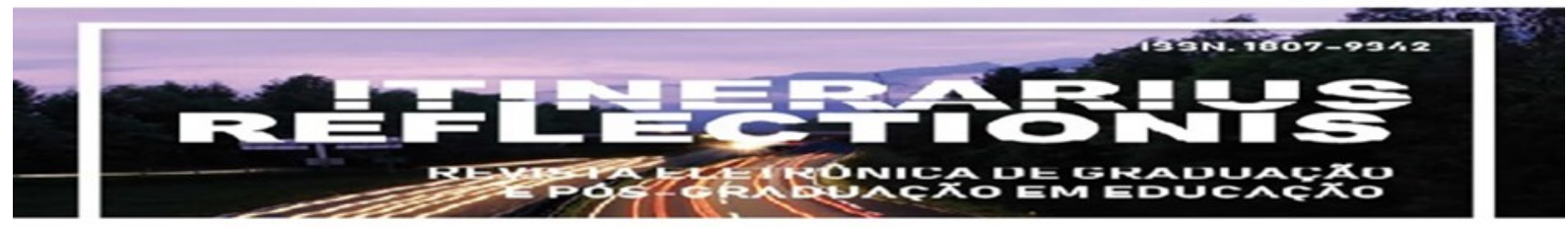

Volume 15, número 1, ano,2019

SALES, E. R. S.; PENTEADO, M. G.; MOURA, A. Q. A Negociação de Sinais em Libras como Possibilidade de Ensino e de Aprendizagem de Geometria. BOLEMA (Boletim de Educação Matemática). v.29, n. 53, não paginado, 2015.

SANCHES, I.; TEODORO, A. Da integração à inclusão escolar: cruzando perspectivas e conceitos. Revista Lusófona de Educação, n.8, p.63-83. 2006.

SANTOS, R. C.; VIANNA, C. C. S. Observação da revisão de gráficos e tabelas de Estatística adaptados em livros didáticos de Matemática em Braille produzidos pelo Instituto Benjamin Constant. Revista Benjamin Constant. Edição 60, v.1, p. 29-54. 2017.

SILVA, D. C.; LEIVAS, J. C. S. Inclusão no Ensino Médio: Geometria para Deficiente Visual. Educação Matemática em Revista, Brasília, n. 40, p. 13-20, nov. 2013.

TURELLA, C. F.; CONTI, K. C. Matemática e a Deficiência Visual: Atividades Desenvolvidas com o Material Dourado. Revista Benjamin Constant. Edição 52, não paginado, 2012.

ULIANA, M. R. Inclusão de Estudantes Cegos nas Aulas de Matemática: a construção de um kit pedagógico. BOLEMA (Boletim de Educação Matemática). v.27, n. 46, 2013. 